\title{
Research on Mechanisms of Targeted Poverty Alleviation Through Rural Tourism in Sichuan Minority Areas
}

\author{
Fulin Gui ${ }^{1, a}$, Fan Yang ${ }^{1, b}$, Yufeng Wang ${ }^{1, c}$, Shuyue Lei $^{2, d}$ \\ ${ }^{1}$ College of Economics, Sichuan Agricultural University, Chengdu, 611130, China \\ ${ }^{2}$ College of Management, Sichuan Agricultural University, Chengdu, 611130, China \\ aemail, 'email, ${ }^{\mathrm{c} e m a i l,}$,email
}

Keywords: Rural tourism, Community participation, Targeted poverty alleviation, Minority Areas

\begin{abstract}
Rural tourism is an important handle for targeted poverty alleviation in minority areas in Sichuan, and is an important carrier to enhance the hematopoiesis function of targeted poverty alleviation. At present, the problems of targeted poverty alleviation in rural areas of Sichuan minority areas include unclear ideology understanding, low participation degree and imperfect participation mechanism. This paper analyzes the unique advantages of the ecological and cultural resources of Sichuan minority areas, points out the current situation and shortcomings of the develop mechanism of rural tourism from the perspective of community participation, and puts forward some countermeasures in the future. They include stabling rural infrastructure construction, strengthening rural tourism education and training, providing cultural products of rural and pastoral areas, building social participation platform and actively participating in multi-platform marketing.
\end{abstract}

\section{Significance of Targeted Poverty Alleviation Through Rural Tourism in Minority Areas and Tourism Participation of Community}

Significance of Targeted Poverty Alleviation in Minority Areas. Ethnic tourism is the minority nationalities in our country is relatively distinctive Han region natural landscape and unique national culture as an important form of special tourism attraction, which has the characteristics of nationality, culture, communication, and other special. The precise poverty is symmetric extensive poverty, poverty is a pointer to the different regional environment, different situation of poor farmers, using scientific and effective procedures for the implementation of accurate identification, precise poverty, helping the precise management of poor governance mode. National tourism is of great significance to precision poverty alleviation. The minority tourism investment is small and income is great. The joint effect of national tourism industry is remarkable. The national tourism poverty alleviation is durable.

Significance of Tourism Participation of Community. Community participation tourism refers to the important responsibility of community residents to undertake the development of community tourism industry as the protagonist, and share the fruits of tourism development at the same time. Community participation is of great significance to the development of national tourism and the precision poverty alleviation. Community should be the core force of national tourism. The special attraction of national tourism is "special" in the national culture, and the community people are the disseminators and bearers of the unique national culture. Once left the community, the particularity of national tourism will lose its soul. Community participation in tourism is the key node of poverty alleviation in tourism. Only by constructing effective participation mechanism and improving people's ability to participate in tourism can we achieve the results as scheduled.

\section{Current Situation Poverty Alleviation Mechanism through Tourism in Sichuan Minority Areas from the Perspective of Community Participation}

Sichuan ethnic areas because of natural environment, historical and cultural infrastructure, traffic conditions and other factors, poverty, poverty and poverty phenomenon. In recent years, the state has supported and promoted poverty alleviation through tourism, and achieved positive results. But 
through on-the-spot investigation, it is found that there are some problems in national tourism and poverty alleviation, which need to be solved in time to optimize and improve the poverty alleviation effect. Specific questions are as follows:

First, the ideological understanding is not clear enough. The government pay more attention to the investment system, capital investment, and to the community participation in tourism does not understand, do not understand, not enough to study tourism "who support, to help who and how to help", the lack of clear plans and measures; enterprises pay more attention to the interests of the chase, more enthusiastic and government matchmaking for residents to participate in something neglect or indifference; residents as a cultural accomplishment, the ideological level of self-limitation, lack of attention and active participation, more passive waiting, and lack of commodity conception, open concept, learning concept, publicity ideas, new ideas more slowly; residents blindly imitate City construction in commodity development, imitation of modern dishes, not confident of native culture.

Second, planning is too macro. The local government hopes to the development of the tourism industry has become a pillar industry, and promote economic and social development, so the planning work by governments at all levels attach great importance, but limited to develop a macro tourism planning, tourism planning for lack of attention, not to give proper support, poverty alleviation of rural tourism has not been included in the planning of regional tourism development large system. Scenic spots development and product design planning on building, preference facilities, pay more attention to "tourism" instead of "poverty" of poor households, community participation mechanism construction is lack of consideration, unable to provide support for the cause of poverty alleviation and development, planning to receive the actual effect.

Third, participation ability is low. As human capital constraints, the community residents to participate in the tourism industry's ability is low, lack of service consciousness and skills, the overall lack of experience, resulting in poor quality of service, influence the tourism destination overall impression, oneself also can in tourism development and get more profits. As a result of economic backwardness, most poor families lack the basic capital needed to participate in tourism. The stock of human resources and quality problems, as well as the shortage of material capital, directly lead to the overall level of tourism development is low.

Fourth, the participation mechanism is not perfect. Although the entry of foreign enterprises has promoted the development of local tourism, the poverty-stricken population in ethnic areas has not been absorbed, and the number of benefited population has not been absorbed. Due to the limitations of family location, physical capital, appearance features and technical culture, it is difficult for some residents to participate in tourism and cannot get equal opportunities. The problem of income gap is short of solving mechanism. Compensation for the use of land and other resources is less than expected, the loss of individual interests. Lack of understanding of poverty alleviation policy, public information transmission mechanism is not smooth. Long term small-scale peasant business pattern leads to the lack of cooperative consciousness among the community or poor households, and is not conducive to the rapid growth of the market and industry.

\section{Domestic Models and Experiences Summarization}

Models and Experiences of Zhejiang. In recent years, the main experiences of Zhejiang are as follows: firstly, we should try our best to create a rural cultural atmosphere. Not only embodies the traditional elements, but also reflects the modern fashion. The construction of the ancestral hall, restore the pigsty and other facilities, to provide fashionable bar, pay attention to the wooden tables and chairs, coffee, tea and other cattle sty resources to the development of the farmhouse brand. Second, do everything possible to shape the tourist landscape. With historical culture, local conditions and customs, traditional architecture and natural landscape, sightseeing and leisure tourism will be introduced. Third, lengthen the industrial chain. Through the discovery of local tea culture, the development of tea drinks, tea pillows, health care products, tea tasting room and so on, increased the income of local farmers. 
Models and Experiences of Shaanxi. Relying on rich resources, rural tourism in Shaanxi developed rapidly. The main experiences are as follows: firstly, to set up the service quality evaluation standard of farmhouse service and standardize the service management of farmhouse service. Second, differential development. Southern Shaanxi, Northern Shaanxi and Guanzhong each reflect regional characteristics, avoiding style and service and product similarity. Third, highlight the "agriculture" flavor and provide experience tourism. Efforts to show strong local culture, launched local cultural experience activities, allowing visitors to participate in the production of goods and other activities. Fourth, to carry out the quality of rural households to raise 1000 households training project, the village as a unit, by village development, more than 1000 operators involved in training, improve operational capacity.

Models and Experiences of Guangxi. Guangxi has beautiful scenery and rich ethnic culture resources. Relying on resources, community residents have achieved remarkable results in community tourism, attracting tourists from home and abroad. Their experience mainly includes providing more play and strengthening supervision. The project includes the drifting raft, rice farmers, tour guides, hotel management, the sale of goods, such as dance performing arts, commodity consciousness increasingly strong. The phenomenon of violating the interests of local residents to disorderly competition and foreign enterprises, the introduction of articles of association, standardize various business activities; the landscape destruction and pollution phenomenon of governance; typical destinations such as Yangshuo County, the township established tourism station, strengthen regional management.

\section{Mechanism Countermeasures of Tourism Poverty Alleviation of Community Participation in Sichuan Minority Areas}

Stable Infrastructure and Mechanism to Provide Good Public Goods for Community Participation. First of all, according to the current infrastructure is still weak reality, greatly enhance the level of infrastructure services in the development of rural tourism, especially to improve the service quality, health and safety, environmental management, construction of main roads, secondary roads and trails, convenient for tourists to enter; promote the "toilet revolution"; the implementation of health promotion project, to ensure the disinfection, garbage collection and disposal, streetlight settings, communication, medical safety hydropower work; construction of tourist reception center and cultural square, to provide comprehensive service area and recreation area. Secondly, a series of institutional construction and innovation should be carried out. The establishment of Tourism Management Committee, community tourism, rural tourism and other high-end forum conference, for the broad participation of the masses to build the institutional framework; to the extent permitted by law, enacted in accordance with the actual situation of the local policy provisions, to ensure the community participation in the operation and behavior of having laws to develop; benefit allocation scheme, compensation system, to ensure the ecological interests the economic and social and cultural community residents are not affected by the loss, the implementation of community sustainable development strategy and the implementation of community rich synchronization.

Strengthen Education and Training of Tourism Service to Enhance Tourism Ability of Community Participation. Improving the quality of human resources is the key task of community participation in tourism. The main measures include: through training and publicity, so that the community residents to participate in a practical understanding of the benefits of tourism, rural tourism on the importance of improving their lives and future development, to realize the significance of cultural development and ecological protection, and consciously participate in support of tourism development; to carry out the investigation and interview, understand the residents there are difficulties and the required training content, establishment of community participation in tourism planning and programs, especially on how to improve community participation to solve difficulties, and strive to launch customized training; to increase capital investment, the allocation of certain tourism poverty alleviation funds to carry out education and training; to use capital priority and take care of the poor people, the priority of education to improve the quality of participation, get rich 
opportunities, ensure the poor out of poverty through participation in Tourism Take; Professor of higher education teaching, the enterprise on-site guidance, demonstration and other forms, combining theory and practice, to carry out the training work, improve the residents' participation in tourism awareness and concepts, to enhance tourism services and management capacity, improve market competitiveness.

Consider Tourism Market Demand to Provide Cultural Products of Rural and Pastoral Areas. First of all, the integration of tourism market demand and direction of tourism services. The main market in rural tourism in ethnic areas is the city residents, so be sure to highlight the core attraction of rural tourism, especially prominent local flavor and rustic, show the rural honest, friendly and enthusiastic, ecological, novelty. Such as the restoration of the old farm tools, cooking utensils, household goods, provide the shuttlecock, skating, playing basketball and other traditional sports. Secondly, according to different groups to carry out services. The characteristics of tourists in rural tourism are very different. The combination of gender, age, occupation, education, income and preferences provides the services to satisfy their tastes, thus improving the satisfaction and recommendation rate. If the cultural people try to satisfy their cultural curiosity and cultural research needs, the entrepreneurs and leading cadres should try their best to meet their hygienic requirements, arrange more grades, and be more distinctive in service. Thirdly, developing and selling characteristic commodities. Awarding the establishment of tourism product development base to create a set of tourism product development, demonstration, promotion, incubation of integrated professional platform, the local characteristics of fresh fruits and vegetables, poultry and fish, beautiful flowers, bonsai handicrafts to carry out systematic planning and development, carry out rural tourism shopping. Finally, all the efforts should be made to shape and embody cultural traditions and cultural atmosphere.

Build Social Participation Platform to Provide Joint Efforts for Targeted Poverty Alleviation. The first form of rural elite people and groups, to lead the demonstration effect, to stimulate community participation in tourism initiative and enthusiasm, promote the development of community tourism; the establishment of Tourism Association or organic association, and dealing with internal and external affairs, to carry out in the foreign exchange market to accelerate the processing, pay special attention to the conflict between foreign and local interest groups community, community security interests of all kinds; a community meeting, the residents' participation in management decision-making and supervision and evaluation, to protect the residents rights violations do not accept and damage; according to the economics principle of comparative advantage and competitive advantage, combined with the community residents of their own characteristics and expertise, carry out their respective division, engaged in catering services, goods management and other work, to avoid vicious competition; play a "person" effect, the main cultivation of rural tourism elite, the director of the village committee Generally, college-graduate village official use their capital advantage and social relations, a mentoring role for the whole tourism industry and rural poverty.

Actively Participate in Multi-Platform Market to Expand Tourism Markets. First of all, based on the spatial level to carry out tourist market marketing. For close to the market, play distance and traffic advantages, launched a two-day tour, and weekend travel, carry out marketing price, give half price concessions for the elderly and children, part of the tourism product takes the high prices to attract tourists; on long-distance tourist marketing, using advertising effect, establish a positive image of tourism, and also by the government to carry out promotion, achieve the effect of authority and credibility to win. Secondly, to carry out marketing based on market subdivision level, focusing on the use of residents, business, religious pilgrimage holiday travel motivation, bombing to attract residents; finally, we should form the marketing team, preparation of folk culture, rural tourism guide, opening tourism information network and relying on marketing. 


\section{Conclusion}

In short, in the context of a comprehensive deepening of reform, social poverty alleviation goals are more diverse, rural tourism prospects in ethnic areas of Sichuan, with national cultural resources, ecological environment and policy advantages, as long as the community participation, build system, and follow the market trend, scientific planning and draw lessons from foreign experience. We can make a difference in the overall construction of social construction.

\section{References}

[1] Yang Fan, Zhuang Tianhui, Kan Jie, Zeng Weizhong. Evaluation of Tibetan Counties' Economic and Social Development in Sichuan Province [J]. Guizhou Ethnic Studies, 2015, 36(9): 170-173.

[2] Deng Xiaohai. Targeted Poverty Alleviation Through Tourism [J]. Journal of Xinjiang University (Philosophy, Humanities \& Social Science), 2015, 43(6): 21-27.

[3] Xiong Jiazhen, Su Zuqin. Problem Review of Poverty Alleviation through Tourism in China from 1996 to 2016 [J]. Journal of Anhui Agricultural Sciences, 2016, 44(18): 225-228.

[4] Mao Feng. Innovation and Strategy of Rural Tourism Poverty Alleviation [J]. Chinese Journal of Agricultural Resources and Regional Planning, 2016, 37(10): 212-217. 